ARTICLE

\title{
Evaluation of Health Risks due to Natural Radioactivity in Domestic Water Sources from Northern Peninsular Malaysia
}

\author{
Bashir Gide MUHAMMAD ${ }^{1 *}$, Mohammad Suhaimi JAAFAR ${ }^{2}$ \\ ${ }^{I}$ Department of Physics, Umaru Musa Yar'adua University, Katsina, Nigeria. \\ ${ }^{2}$ School of Physics Universiti Sains Malaysia.
}

\begin{abstract}
The World Health Organisation protocol was adopted to screen the adequately utilized surface water resources in northern peninsular Malaysia for radiological safety. Firstly, an eight channel gas flow proportional counting system was employed for gross alpha and gross beta screening using ISO procedures. The gross alpha values were found to fall below the ICRP and WHO recommended MCL of $500 \mathrm{Bqm}^{-3}$ while the gross beta values in some samples exceeds the MCL value of $1000 \mathrm{Bqm}^{-3}$. Gamma spectroscopy was then employed to determine the natural radionuclides responsible for the elevated activity concentration values. A fixed volume close-loop extraction of radon from water to air which is a convenient and reliable method was also used to measure ${ }^{222} \mathrm{Rn}$ activity concentration in the water. Relatively high radon concentrations were obtained in some raw water sources compared to that from other parts of the world, which still falls below the WHO recommended treatment level of $100 \mathrm{Bql}^{-1}$. Subsequently, UNSCEAR dose conversion factors were used to estimate the committed effective dose due to these radionuclides so as to ascertain the health risk level of using the water for drinking purposes.
\end{abstract}

KEY WORDS: gross alpha, gross beta, norm activity concentration, domestic water, committed effective dose.

\section{Introduction}

The presence of radionuclides in water poses a number of health hazards, especially when these radionuclides are deposited in the human body through drinking. Dissolved radionuclides in water emit particles (alpha and beta) and photons (gamma) which gradually expose living tissues ${ }^{1-3)}$. Human and animal studies show that radiation exposure at low to moderate doses may increase the long-term incidence of cancer ${ }^{4-6)}$. Studies have also shown that there is no safe radiation dose; accumulation of radionuclides in the body overtime may lead to several types of cancers ${ }^{7)}$. The potential adverse effect from ingestion of radionuclides, through drinking water, requires a standard to be set in order to protect the members of public from radiation exposure above permissible levels. The World Health Organizations' guidelines for drinking-water quality recommended the determination of gross alpha and gross beta activity concentrations in drinking water as the first step of the radiological aspect of the drinking water quality ${ }^{8)}$. Generally, radiation exposure due to gross alpha is of greater concern than that due to gross beta for natural radioactivity ${ }^{9)}$. This is due to the high LET nature of alpha particles which gives them the ability to deposit larger amount of energy within a small distance in a medium. The essence of the evaluation of the gross alpha and gross beta activities is to ensure that the reference dose level (RDL) of committed

\footnotetext{
* Corresponding Author, Email: bashirgide@umyu.edu.ng @,2012 Atomic Energy Society of Japan. All rights reserved
}

effective dose of $0.1 \mathrm{mSv}$ from 1 year's consumption of drinking water is not exceeded. The RDL of $0.1 \mathrm{mSv}$ is equal to $10 \%$ of the dose limit for members of the public, recommended by the International Commission for Radiological Protection (ICRP, 1991) and the International Basic Safety Standards (IAEA, 1996) and are acceptable to most World Health Organizations (WHO) Member States, European Commission, Food and Agriculture Organization. The recommendation is also adopted by the Malaysian drinking water quality standards (NDWQS) to ensure that an MCL (Maximum Concentration Limit) of $500 \mathrm{Bqm}^{-3}$ and $1000 \mathrm{Bqm}^{-3}$ for gross alpha and gross beta respectively are not exceeded. The focus of this stage of the study was therefore to evaluate the gross alpha and beta radioactivities in the domestic water sources from northern peninsular Malaysia and also to establish the distribution pattern of radioactivity measured in the area so as to ascertain the safety of the water for drinking and other domestic purposes.

\section{Materials and Methods}

1. Counting equipment for gross alpha and gross beta measurements

The counting system employed for gross alpha and gross beta measurement is a gas-flow proportional counter (EURISYS MEASURE IN20 Low Background multiple (eight) channel counter). The system is connected to a micro processor loaded with a spreadsheet programme (QUARTTRO-PRO) and graphic programme 
(MULTIPLAN). Details of this counter were described earlier ${ }^{10)}$. The $\alpha$ - Standards used were Plutonium - 239 (halflife $=24,200$ years, alpha decay energy $=5.245 \mathrm{MeV}$ ) with reference numbers EBS 20/50050-57. The $\beta$ Standards were Strontium -90 half-life $=28.8$ years, beta decay energy $=$ $0.546 \mathrm{MeV}$ ) with reference numbers EBS 20/145 29-39. These standards were certified by CERCA LEA Laboratories in France with certificate numbers CT 001/1285/001920-1927 and CT 1271/00/1778 - 1783 respectively.

\section{Radioelemental analysis using NaI(Tl) gamma spectroscopic system}

The radioelemental analysis was carried out using a high efficiency "7.6 cm (3") diam x $7.6 \mathrm{~cm}$ (3") long $\mathrm{NaI}(\mathrm{Tl})$ scintillation detector (ORTEC) connected to a $7.6 \mathrm{~cm}$ (3") photomultiplier. The use of $\mathrm{NaI}(\mathrm{Tl})$ in measurement of activity concentrations in water was reported earlier $9,11,12$. The system has high relative efficiency of about $50 \%$ and a resolution (FWHM) of about $7.2 \%$ at energy of $0.662 \mathrm{MeV}$ $\left({ }^{137} \mathrm{Cs}\right)$ which is considered adequate to distinguish the gamma ray energies of interest in this work. The spectral analysis and peak fitting were performed using Fitzpeak $\mathrm{NaI}(\mathrm{Tl})$ (low resolution) gamma callibration and analysis software developed by JF Scientific UK. This software is specially optimised to be used for low resolution gamma spectra acquired by $\mathrm{NaI}(\mathrm{Tl})$ detectors.

The energy calibration was carried out using IAEA certified standards of known activities such as ${ }^{60} \mathrm{Co}$, for $\mathrm{E}_{\gamma}=$ 1332.5. and $1173.2 \mathrm{keV}$, and ${ }^{137} \mathrm{Cs}$, for $\mathrm{E}_{\gamma}=661.6 \mathrm{keV}$. The efficiency calibration was also performed by using ${ }^{152} \mathrm{Eu}$ standard $^{13,14)}$ for $\mathrm{E}_{\gamma}=121.8,224.7,344.3$, 778.9, 964.0, $1085.8,1112.0$ and $1408.0 \mathrm{keV}$. The gamma line of 1460.8 $\mathrm{keV}$ was used directly to determine ${ }^{40} \mathrm{~K}$. The weighted mean activity concentrations from gamma lines of $911.1 \mathrm{keV}$ $\left({ }^{228} \mathrm{Ac}\right)$ and $583.1 \mathrm{keV}\left({ }^{212} \mathrm{~Pb}\right)$ were used to determine ${ }^{232} \mathrm{Th}$. The gamma lines of $351.9 \mathrm{keV}\left({ }^{214} \mathrm{~Pb}\right)$ and $609.3 \mathrm{keV}$ $\left({ }^{214} \mathrm{Bi}\right)$ were used to determine ${ }^{238} \mathrm{U}$ and $186.1 \mathrm{keV}\left({ }^{226} \mathrm{Ra}\right)$ gives the activity concentration of ${ }^{226} \mathrm{Ra}$ as a natural source.

\section{Estimation of committed effective dose}

Effective dose is based on the risks of radiation induced health effects and the use of the International Commission on Radiological Protection (ICRP) metabolic model that provides relevant conversion factors to calculate effective doses from the total activity concentrations of radionuclides measured. The dose arising from the intake of $1 \mathrm{~Bq}$ (by ingestion) of radioisotope in a particular chemical form can be estimated using a dose conversion factor (DCF). Data for age-related dose conversion factors for ingestion of radionuclides has been published by the International Commission on Radiological Protection (ICRP 1996) ${ }^{15)}$.

\section{Results and Discussions}

Gross alpha and gross beta analysis was carried out by adopting the procedure proposed by international standards $\operatorname{organization}^{16,17)}$. The results as depicted by Figure 1 and 2. The horizontal dotted lines being the MCL set by both WHO and ICRP above which further screening is recommended.

gross alpha activity concentration

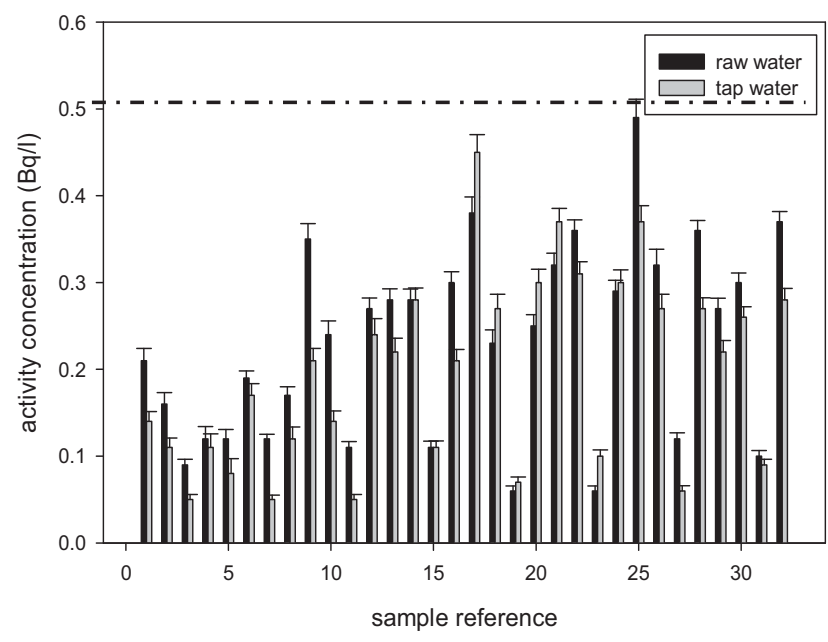

Fig. 1 Gross alpha activity concentration in raw and treated water from northern peninsular Malaysia.

gross beta activity concentration

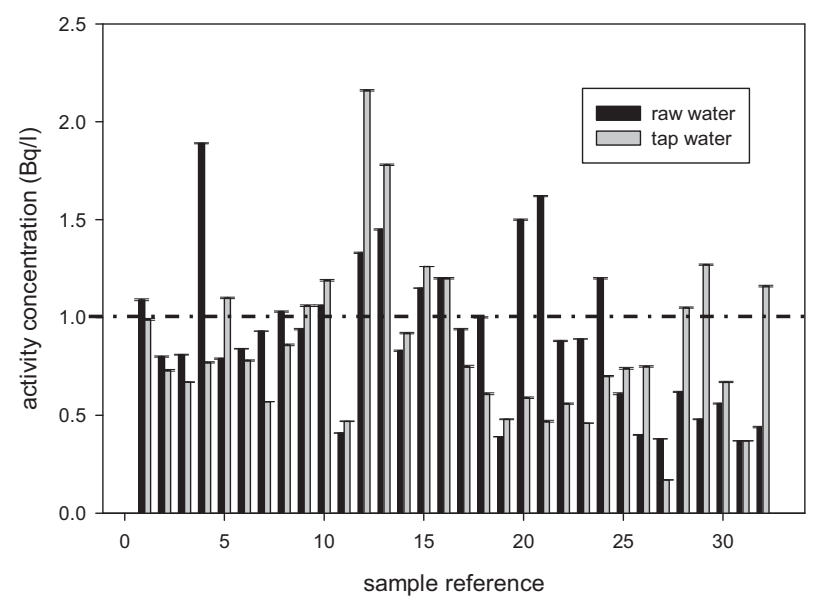

Fig. 2 Gross beta activity concentration in raw and treated water from northern peninsular Malaysia.

The gross beta values in some samples still exceed the MCL even after treatment when compared with the ICRP and WHO proposed MCL values of $500 \mathrm{Bqm}^{-3}$ and 1000 $\mathrm{Bqm}^{-3}$ which were similarly adopted by the Malaysian Water Quality Surveillance Unit in its National Drinking Water Quality Standards (NDWQS).

The activity concentration of natural radionuclides in the raw and treated domestic water supply in northern peninsular Malaysia is presented in Table $\mathbf{1}$ and $\mathbf{2}$ respectively. 
Table 1 Activity concentration $\left(\mathrm{Bqm}^{-3}\right)$ in raw water sources in the study area.

\begin{tabular}{llllll}
\hline Location & $\begin{array}{l}\text { Sample } \\
\text { size }\end{array}$ & ${ }^{238} \mathbf{U}$ & ${ }^{232} \mathbf{T h}$ & ${ }^{40} \mathbf{K}$ & \\
\hline Penang & 11 & $3,108 \pm 361$ & $3,326 \pm 320$ & $12,811 \pm 990$ & $12,358 \pm 791$ \\
Perlis & 12 & $2,110 \pm 272$ & $4,679 \pm 290$ & $8,875 \pm 610$ & $2,734 \pm 189$ \\
Kedah & 8 & $1,921 \pm 263$ & $2,893 \pm 155$ & $8,520 \pm 578$ & $2,621 \pm 181$ \\
Perak & 8 & $4,023 \pm 499$ & $2,407 \pm 501$ & $18,437 \pm 1,261$ & $5,660 \pm 377$ \\
Mean & & $\mathbf{2 , 7 9 1} \pm \mathbf{3 4 9}$ & $\mathbf{3 , 3 2 6} \pm \mathbf{3 1 7}$ & $\mathbf{1 2 , 1 6 1} \pm \mathbf{8 6 0}$ & $\mathbf{5 , 8 4 3} \pm \mathbf{3 8 5}$ \\
\hline
\end{tabular}

Table 2 Activity concentration $\left(\mathrm{Bqm}^{-3}\right)$ in treated domestic water supply in the study area.

\begin{tabular}{llllll}
\hline Location & $\begin{array}{l}\text { Sample } \\
\text { size }\end{array}$ & ${ }^{238} \mathbf{U}$ & ${ }^{232} \mathbf{T h}$ & ${ }^{40} \mathbf{K}$ & ${ }^{22} \mathbf{R a}$ \\
\hline Penang & 11 & $97 \pm 9$ & $110 \pm 7$ & $1,465 \pm 95$ & $289 \pm 18$ \\
Perlis & 12 & $88 \pm 9$ & $113 \pm 7$ & $1,526 \pm 95$ & $310 \pm 19$ \\
Kedah & 8 & $79 \pm 4$ & $120 \pm 7$ & $1,455 \pm 100$ & $310 \pm 18$ \\
Perak & 8 & $91 \pm 10$ & $122 \pm 7$ & $1,529 \pm 78$ & $332 \pm 12$ \\
Mean & & $\mathbf{8 9} \pm \mathbf{8}$ & $\mathbf{1 1 6} \pm 7$ & $\mathbf{1 4 9 4} \pm \mathbf{9 2}$ & $\mathbf{3 1 0} \pm \mathbf{1 7}$ \\
\hline
\end{tabular}

Raw water samples from Perak, an area known for its tin mining activities are known to contain uranium and thorium as earlier reported by Bahari et al. ${ }^{18)}$, were found to have higher average activity concentration values of $4,023 \pm 499$, $2,407 \pm 501,18,437 \pm 1,261$ and $5,660 \pm 377 \mathrm{Bqm}^{-3}$ in the raw water. The activity concentration in the treated water from Perak also shows higher mean values of $91 \pm 10,122 \pm 7$, $1,529 \pm 78$ and $332 \pm 12 \mathrm{Bqm}^{-3} .{ }^{40} \mathrm{~K}$ indicated the highest activity concentration values in both the raw and treated water in the area. The highest mean value of ${ }^{226} \mathrm{Ra}$ $\left(12,358 \pm 791 \mathrm{~Bq} \mathrm{~m}^{-3}\right)$ in the raw water was also observed in Penang. This value comes in agreement with the earlier reported moderate ${ }^{222} \mathrm{Rn}$ values (but less than WHO action level of $\left.100 \mathrm{~Bq}^{-1}\right)^{8)}$ in the Penang region by Muhammad et $a l .{ }^{19)}$. The total committed effective dose due to one year's direct ingestion of the treated surface water from the area as a consequence of the identified radionuclides were found to fall within the acceptable range (RDL) of $0.1 \mathrm{mSv} \mathrm{y}^{-1}$ for both the babies (age $<1 \mathrm{y}$ ), children (age 2-7 y) and adults (age $>17 y$ ).

\section{Conclusion}

The results indicated that the gross alpha activity concentration in the raw water samples analyzed are low compared with the MCL. The gross beta values in some samples still exceed the MCL even after treatment when compared with the NDWQS. Comparatively, the moderate activity concentration values in some of the raw water samples from the area, with the highest mean values recorded in Perak, are attributable to the presence of amang tin tailings and other post mining deposits in the area, as well as the nature of the water sources, that is, high residence time resulting in more dissolved solids in case of still water sources (dams and reservoirs) and wash off and leaching in case of moving water sources (rivers) in the area. The high radium concentrations observed in Penang also justify the high water-borne radon activity concentrations in the area. Despite the fact that the concentrations of natural radioisotopes and subsequent committed effective doses (in some samples) were substantially higher than those in some other populations, most still remained low when compared with recommended intervention limits. The magnitude of risk expected in our study is therefore small.

\section{Acknowledgement}

Financial support was provided by Postgraduate Research Grant Scheme (PRGS), Universiti Sains Malaysia and Umaru Musa Yar'adua University, Katsina Nigeria.

\section{References}

1) Alam, M.N.C., M.I. Kamal,M. Ghose,S. Islam,M.N. and Anwaruddin,M., Radiological assessment of drinking water of the chittagong region of Bangladesh Radiation Protection Dosimetry, 1999. 82(3): p. 207-14.

2) Dalma, N., et al., Gross alpha and beta activities in tap waters in Eastern Black Sea region of Turkey. Chemosphere, 2006. 62: p. 956-960.

3) Gruber, V., F.J. Maringer, and C. Landstetter, Radon and other natural radionuclides in drinking water in Austria: measurement and assessment. Appl Radiat Isot, 2009. 67(5): p. 913-7.

4) Abo, M., et al., Cytogenetic effects of radon inhalation. Radiation Measurements, 2008. 43: p. 1265 - 1269.

5) Collman, G.W., D.P. Loomis, and D.P. Sandler, Childhood cancer mortality and radon concentration in drinking water in North Carolina. Br J Cancer, 1991. 63(4): p. 626-9.

6) Amrani, D. and D.E. Cherouati, Health effects from radon222 in drinking water in Algiers. J Radiol Prot, 1999. 19(3): p. 275-9.

7) Auvinen, A., et al., Radon and other natural radionuclides in drinking water and risk of stomach cancer: a case-cohort study in Finland. Int J Cancer, 2005. 114(1): p. 109-13.

8) WHO, Guidelines for Drinking-water Quality. World Health Organisation Publiation, 2008. 1: p. 197-209. 
9) Bonotto, D.M. and T.O. Bueno, The natural radioactivity in Guarani aquifer groundwater, Brazil. Appl Radiat Isot, 2008. 66(10): p. 1507-22.

10) Muhammad, B.G., M.S. Jaafar, and T.C. Akpa, A survey of gross alpha and beta activity concentrations in groundwater from Katsina area of Northern Nigeria. Radiat Prot Dosimetry, 2010. 141(2): p. 127-33.

11) Tsabaris, C., Monitoring natural and artificial radioactivity enhancement in the Aegean Sea using floating measuring systems. Appl Radiat Isot, 2008. 66(11): p. 1599-603.

12) Bonotto, D.M., et al., The natural radioactivity in water by gross alpha and beta measurements. Radiation Measurements, 2009. 44(1): p. 92-101.

13) ISO, Measurement of radioactivity in the environment, in Measurement of gammaemitting radionuclides. 2007, ISO. p. 30.

14) Fatima, I., et al., Measurement of natural radioactivity in bottled drinking water in Pakistan and consequent dose estimates. Radiat Prot Dosimetry, 2007. 123(2): p. 234-40.
15) UNSCEAR, Dose assessment methodologies, in SOURCES AND EFFECTS OF IONIZING RADIATION. 2000, UNSCEAR. p. 63.

16) ISO, Water Quality - Measurement of Gross Alpha activity in non saline water. . 1992. ISO 9696.

17) ISO, Water Quality - Measurement of Gross Beta activity in non saline water. International Organization for Standardization. . 1992. ISO 9697.

18) Bahari, I., N. Mohsen, and P. Abdullah, Radioactivity and radiological risk associated with effluent sediment containing technologically enhanced naturally occurring radioactive materials in amang (tin tailings) processing industry. J Environ Radioact, 2007. 95(2-3): p. 161-70.

19) Muhammad, B.G., et al., Measurements of 222rn Activity Concentration in Domestic Water Sources in Penang, Northern Peninsular Malaysia. Radiat Prot Dosimetry, 2011. 